\title{
Radiation Therapy Prophylaxis for Heterotopic Ossification in Non-Hip Sites
}

\author{
Ajaykumar B. Patel ${ }^{1 *}$, Katherine S. Tzou ${ }^{2}$, Megan Single ${ }^{3}$, Laeticia Hollant ${ }^{4}$, Bridget Smart ${ }^{5}$, \\ Katherine Gaines6, Courtney E. Sherman7, Jennifer L. Peterson'2, Stephen J. Ko², \\ Laura A. Vallow ${ }^{2}$, Robert C. Miller ${ }^{2}$, Steven J. Buskirk² \\ ${ }^{1}$ Northside Radiation Oncology Consultants, Atlanta, GA, USA \\ ${ }^{2}$ Department of Radiation Oncology, Mayo Clinic, Jacksonville, FL, USA \\ ${ }^{3}$ College of Medicine, University of Kentucky, Lexington, KY, USA \\ ${ }^{4}$ University of Central Florida, Orlando, FL, USA \\ ${ }^{5}$ University of Florida, Gainesville, FL, USA \\ ${ }^{6}$ University of North Florida, Jacksonville, FL, USA \\ ${ }^{7}$ Department of Orthopedic Surgery, Mayo Clinic, Jacksonville, FL, USA \\ Email: *jaykumarbpatel@gmail.com
}

How to cite this paper: Patel, A.B., Tzou, K.S., Single, M., Hollant, L., Smart, B., Gaines, K., Sherman, C.E., Peterson, J.L., Ko, S.J., Vallow, L.A., Miller, R.C. and Buskirk, S.J. (2018) Radiation Therapy Prophylaxis for Heterotopic Ossification in Non-Hip Sites. Journal of Cancer Therapy, 9, 1-8. https://doi.org/10.4236/jct.2018.91001

Received: November 14, 2017

Accepted: January 2, 2018

Published: January 5, 2018

Copyright $\odot 2018$ by authors and Scientific Research Publishing Inc. This work is licensed under the Creative Commons Attribution International License (CC BY 4.0).

http://creativecommons.org/licenses/by/4.0/

\begin{abstract}
Background: Radiation therapy prophylaxis for heterotopic ossification is well-established for the hip, either pre or post-operatively. There is limited data for this treatment in non-hip sites. We report our institution's experience. Methods: From October 2004 to August 2015, a total of 39 non-hip sites in 38 patients were treated with prophylactic radiation therapy for heterotopic ossification at our institution. An IRB approved retrospective review was performed. There were 15 patients who received treatments to the elbow, 13 to the knee (1 bilateral for a total of 14 knees), and 10 to other sites (leg stump (2), pubic symphysis (2), femur (1), foot (1), humerus stump (1), abdominal wall (1), shoulder (1), thigh (1)). All but 1 patient were treated with a single fraction treatment with 700 or 800 cGy. One patient received 2000 cGy in 10 fractions to the abdominal wall for heterotopic ossification extending from the xiphoid process. Results: Fifteen patients underwent treatment to the elbow with a median follow-up of 5 months $(0-99)$. Median age for this group was 50 years $(37-69)$. Nine $(60.0 \%)$ patients had evidence of heterotopic ossification prior to surgery. All (100\%) of the elbow patients were free from recurrence at last follow-up. There were no acute or late toxicities noted. For treatment to the knee, there were 4 (28.6\%) recurrences, all in cases where there were pre-operative heterotopic ossification. There were two other recurrences in the non-hip, elbow or knee sites: one patient who received radiation therapy to the abdominal wall and one patient who underwent treatment to the thigh. Conclusions: Prophylactic radiation therapy with 700 cGy or 800
\end{abstract}


cGy in 1 fraction either before or after surgery remains a safe and effective treatment for both hip and most non-hip sites. Fractionated treatment may be used for larger treatment fields, however experience is limited.

\section{Keywords}

Heterotopic Ossification, Radiation Therapy, Knee, Elbow

\section{Introduction}

Heterotopic ossification (HO) is the development of bone in soft tissue. It can develop in various sites around the body, usually in a postoperative or post-traumatic setting near a joint space. Heterotopic ossification can affect quality of life with symptoms including pain, swelling, and loss of joint motion. Rates of $\mathrm{HO}$ formation vary by risk factors, including history of previous $\mathrm{HO}$ or fracture. Radiation therapy (RT) is well-established in high-risk patients for prevention of $\mathrm{HO}$ development for the hip [1]. There are multiple randomized controlled trials showing that 7 Gy in 1 fraction within 72 hours of surgery decreases the risk of development of HO in these patients [2] [3] [4].

Prophylactic RT has been used in non-hip sites including the elbow and knee; however, this data is more limited [5]. O of the elbow can occur in up to 56\% of patients with a radial head fracture [6]. For patients with a dislocation with an associated fracture, rates can be 5\% - 20\% [7]. Recurrence after excision has not been well documented. There is no standard recommendation for the role of RT prophylaxis for $\mathrm{HO}$ of the elbow.

Literature for $\mathrm{HO}$ of the knee is even less common. There are multiple case reports and a retrospective study with 12 patients [8]-[15]. The development of HO has been noted after total knee arthroplasty in up to approximately $40 \%$ of patients [9] [10] [11] [12]. HO of the knee can also occur after dislocation, most notably after posterior cruciate ligament reconstruction [16]. The disease is typically characterized by bony formation near the quadriceps expansion and can result in pain or loss of mobility [13] [14] [15]. Prophylactic radiotherapy for the knee has not been well reported.

Overall, there is limited data for radiation prophylaxis outside of the hip. In this study, we report our institution's experience with use of RT for prophylaxis of $\mathrm{HO}$ in non-hip sites.

\section{Methods}

After obtaining IRB approval, a query was performed for patients with a diagnosis of heterotopic ossification treated with radiation therapy in our department. A review of electronic medical records including treatment records was performed. Our search found 255 patients who had either preoperative or postoperative prophylactic RT for $\mathrm{HO}$ at our institution from October 2004 to August 2015. Of those 255 patients, 218 received treatment to the hip, 15 to the elbow, 13 to the 
knee ( 1 bilateral for a total of 14 knees), and 10 to other sites ( 2 leg stump, 2 pubic symphysis, 1 femur, 1 foot, 1 humerus stump, 1 abdominal wall, 1 shoulder, 1 thigh). Patient data including demographics, radiation and surgery details, acute and chronic toxicities, and follow-up were collected on all patients. We report local failure and toxicity.

All patients were treated with linear accelerators using photons with anterior-posterior-posterio-anterior (AP-PA) beams.

Data analysis was conducted using JMP statistical software (SAS Institute Inc., Cary, North Carolina).

\section{Results}

A total of 39 non-hip sites in 38 patients were treated with prophylactic RT for $\mathrm{HO}$ at our institution. A breakdown of sites is shown in Table 1. All but 1 patient were treated with a single fraction to 700 or $800 \mathrm{cGy}$. The exception was treated with $2000 \mathrm{cGy}$ in 10 fractions to $\mathrm{HO}$ extending from the xiphoid process to the abdominal wall.

\subsection{Elbow}

Fifteen patients underwent treatment to the elbow with a median follow-up of 5 months (0 - 99). Median age for this group was 50 years (37 - 69). Nine (60.0\%) patients had evidence of $\mathrm{HO}$ prior to surgery. Types of surgeries are listed in $\mathrm{Ta}$ ble 2. Thirteen (86.7\%) patients had RT postoperatively. Two patients (13.3\%) had treatment preoperatively. All (100\%) patients were free from recurrence at follow-up. There were no acute or late toxicities noted.

\subsection{Knee}

Thirteen patients received treatment to a total of 14 knees ( 1 patient had bilateral knee treatment). The median follow-up was 21.5 months $(1-110)$. Median age for this group was 66.5 years $(21-81)$. Eight $(61.5 \%)$ patients had evidence of preoperative HO. All knees were treated with postoperative RT receiving 700

Table 1. A breakdown by anatomic site shows most common non-hip sites treated.

\begin{tabular}{cc}
\hline Anatomical Site & Number Treated \\
\hline Elbow & 15 \\
Knee & 14 \\
Femur/femur stump & 4 \\
Non-hip joint pelvic bone & 2 \\
Humerus stump & 1 \\
Shoulder & 1 \\
Abdomen & 1 \\
Foot & 1
\end{tabular}


Table 2. A breakdown of surgeries shows the most common elbow surgery was elbow arthroplasty.

\begin{tabular}{cc}
\hline Surgery/Procedure & Number of Patients \\
\hline Elbow arthroplasty & 8 \\
Heterotopic debridement & 2 \\
Open reduction and/or fixation & 2 \\
Radial ulnar synostosis takedown & 2 \\
Contracture release & 1 \\
\hline
\end{tabular}

cGy in 1 fraction. There were 4 (28.6\%) recurrences, all in cases where preoperative $\mathrm{HO}$ was noted. Two of the recurrences occurred in the same patient who had bilateral RT after bilateral knee manipulation. This patient had bilateral total knee arthroplasty 48 days prior to this knee manipulation and subsequent RT. She then underwent $\mathrm{HO}$ excision the following year. The recurrences are outlined in Table 3. There were no acute or late toxicities noted.

\subsection{Other Sites}

There were 10 patients who received RT to non-hip, elbow, or knee sites. These sites are outlined in Table 4. There were 2 recurrences in this group: 1 patient received $\mathrm{RT}$ to the abdominal wall, and 1 underwent treatment to the thigh. The patient who received RT to the abdominal wall had myositis ossificans extending from the xiphoid process to the pubic symphysis. His disease developed after significant abdominal wall trauma. Figure 1 shows this patient's extent of disease. He received $2000 \mathrm{cGy}$ in 10 fractions.

\section{Discussion}

Radiation therapy (RT) for prophylaxis of heterotopic ossification (HO) for the hip is well-established [1] [2] [3] [4]. The same therapy for other sites is not as widely reported. In this article, we add to the growing body of literature for knee, elbow, and other sites that are at high-risk for developing $\mathrm{HO}$.

In our study, patients who received RT to the elbow had no HO recurrences and no toxicities, demonstrating that this treatment is safe and effective. Other reports for RT to the elbow found similar results [17]. A study from Cleveland Clinic reported on 36 patients who underwent surgery and postoperative single-fraction RT [18]. They found that only 3 (8\%) of the patients developed new HO after therapy. A study from Rush University in 2011 evaluated 44 patients who underwent RT after surgery to the elbow and had post-therapy radiographs [19]. They found at a follow-up of 136 days that 21 (48\%) of the patients had developed HO.

We had similar outcomes with patients undergoing treatment to the knee. While 4 (28.6\%) patients experienced recurrent disease, all of them had evidence of $\mathrm{HO}$ prior to surgery. One patient who had bilateral recurrence had knee 
Table 3. Three patients had knee recurrences with time to progression ranging from 1 to 13 months.

\begin{tabular}{ccccc}
\hline Patient & Surgery/Procedure & Time to RT & $\begin{array}{c}\text { Preoperative } \\
\text { HO }\end{array}$ & $\begin{array}{c}\text { Time to } \\
\text { Recurrence/Progression }\end{array}$ \\
\hline 1 & $\begin{array}{c}\text { Revision of total knee } \\
\text { arthroplasty }\end{array}$ & 1 day & Present & 13 months \\
2 & Total knee arthroplasty & $<1$ day & Present & 1 month \\
3 & $\begin{array}{c}\text { Bilateral knee } \\
\text { manipulation }\end{array}$ & 2 days & $\begin{array}{c}\text { Present } \\
\text { (bilateral) }\end{array}$ & 1 month \\
\hline
\end{tabular}

HO: Heterotopic ossification; RT: Radiation therapy.

Table 4. Other sites.

\begin{tabular}{|c|c|c|c|}
\hline Site & Type of Surgery & $\begin{array}{c}\text { Radiation } \\
\text { Dose/Fraction }\end{array}$ & Recurrence? \\
\hline $\begin{array}{l}\text { Iliac crest and pubic } \\
\text { symphysis }\end{array}$ & HO excision & $700 \mathrm{cGy} / 1 \mathrm{fx}$ & No \\
\hline $\begin{array}{l}\text { Superior pubic ramus } \\
\text { and obturator foramen }\end{array}$ & HO excision & $700 \mathrm{cGy} / 1 \mathrm{fx}$ & No \\
\hline Femur & HO excision & $700 \mathrm{cGy} / 1 \mathrm{fx}$ & No \\
\hline Femur & HO excision & $700 \mathrm{cGy} / 1 \mathrm{fx}$ & Yes \\
\hline Femur stump & $\begin{array}{l}\text { Above-the-knee } \\
\text { amputation }\end{array}$ & $700 \mathrm{cGy} / 1 \mathrm{fx}$ & No \\
\hline Femur stump & $\begin{array}{l}\text { Above-the-knee } \\
\text { amputation }\end{array}$ & $700 \mathrm{cGy} / 1 \mathrm{fx}$ & No \\
\hline Foot & HO excision & $700 \mathrm{cGy} / 1 \mathrm{fx}$ & No \\
\hline Abdomen & HO excision & $2000 \mathrm{cGy} / 10 \mathrm{fx}$ & Yes \\
\hline Humerus stump & $\begin{array}{l}\text { Above-the-elbow } \\
\text { amputation, HO excision }\end{array}$ & $700 \mathrm{cGy} / 1 \mathrm{fx}$ & No \\
\hline Shoulder & HO excision & $700 \mathrm{cGy} / 1 \mathrm{fx}$ & No \\
\hline
\end{tabular}

HO: Heterotopic ossification.

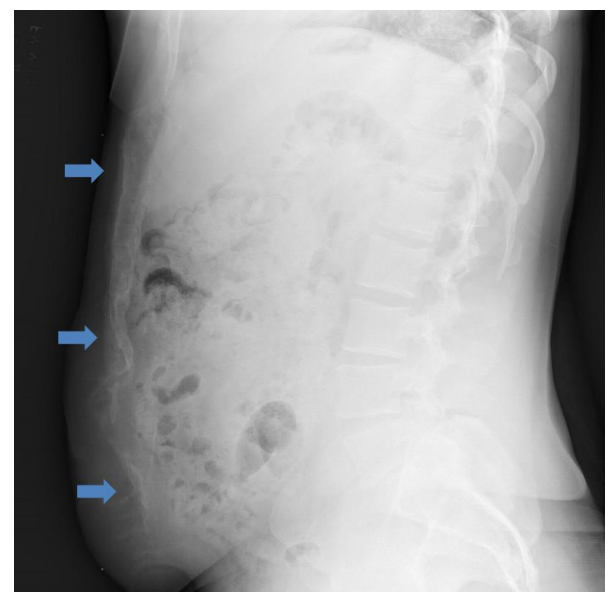

Figure 1. This image is a lateral X-ray of abdominal heterotopic ossification in a 40-year-old male with myositis ossificans extending from the xiphoid process to the pubic symphysis (blue arrows). 
manipulation and RT 48 days after an initial bilateral arthroplasty. There was no report of $\mathrm{HO}$ excision at the time of knee manipulation prior to RT. This leads to the question of whether or not the timing of RT this late after bilateral arthroplasty contributed to this patient having recurrence and progression of disease. Overall, there were no toxicities, acute or late, noted.

One report from Drexel University with 12 patients who underwent RT for knee HO prophylaxis had no HO recurrence after treatment [8]. This patient group differed from ours as $8(61.5 \%)$ of our patients versus none of their patients had evidence of $\mathrm{HO}$ prior to surgery. A report by Chidel et al. detailed their experience with 5 patients who received knee HO prophylaxis with RT [13]. They had no progression or recurrence of $\mathrm{HO}$, reporting that the treatment was well tolerated.

Although acute side effects are minimal, the risk for secondary malignancy is always an important concern in the treatment of benign disorders. There have been case reports for developing soft tissue sarcomas within the field of single-fraction RT for HO [20] [21]. However, none of the larger series of both hip and non-hip sites have shown any evidence of the development of secondary malignancy within the treatment field. A study by Berris et al. outlined peripheral organ doses from radiotherapy for non-hip sites [22]. They found for shoulder, elbow, and knee treatments that equivalent peripheral organ doses were $0.85-62 \mathrm{mSv}, 0.28-1.6$ $\mathrm{mSv}$, and $0.04-1.6 \mathrm{mSv}$, respectively. This corresponded to cancer risks of 0 5.1, $0-0.6$, and $0-1.3$ cases per 10,000 persons. The highest risks were with treatment to the shoulder in developing malignancies of skin (5.1 cases per 10,000) and breast (3.8 cases per 10,000). Though the risk for secondary malignancy remains, it is evidently extremely rare, especially in elbow and knee treatments.

A noted obvious limitation of this study is its retrospective nature and heterogeneous patient cohort.

\section{Conclusion}

RT prophylaxis with $700 \mathrm{cGy}$ in 1 fraction either before or after surgery remains a safe and effective treatment for both hip and most non-hip sites.

\section{References}

[1] Pakos, E.E. and Ioannidis, J.P. (2004) Radiotherapy vs. Nonsteroidal Anti-Inflammatory Drugs for the Prevention of Heterotopic Ossification after Major Hip Procedures: A Meta-Analysis of Randomized Trials. International Journal of Radiation Oncology, Biology, Physics, 60, 888-895. https://doi.org/10.1016/j.ijrobp.2003.11.015

[2] Seegenschmiedt, M.H., Keilholz, L., Martus, P., et al. (1997) Prevention of Heterotopic Ossification about the Hip: Final Results of Two Randomized Trials in 410 Patients Using either Preoperative or Postoperative Radiation Therapy. International Journal of Radiation Oncology, Biology, Physics, 39, 161-171. https://doi.org/10.1016/S0360-3016(97)00285-X

[3] Kolbl, O., Knelles, D., Barthel, T., Raunecker, F., Flentje, M. and Eulert, J. (1998) Preoperative Irradiation versus the Use of Nonsteroidal Anti-Inflammatory Drugs for Prevention of Heterotopic Ossification Following Total Hip Replacement: The 
Results of a Randomized Trial. International Journal of Radiation Oncology, Biology, Physics, 42, 397-401. https://doi.org/10.1016/S0360-3016(98)00204-1

[4] Seegenschmiedt, M.H., Makoski, H.B. and Micke, O. (2001) Radiation Prophylaxis for Heterotopic Ossification about the Hip Joint-A Multicenter Study. International Journal of Radiation Oncology, Biology, Physics, 51, 756-765. https://doi.org/10.1016/S0360-3016(01)01640-6

[5] Mishra, M.V., Austin, L., Parvizi, J., Ramsey, M. and Showalter, T.N. (2011) Safety and Efficacy of Radiation Therapy as Secondary Prophylaxis for Heterotopic Ossification of Non-Hip Joints. Journal of Medical Imaging and Radiation Oncology, 55, 333-336. https://doi.org/10.1111/j.1754-9485.2011.02275.x

[6] Ilahi, O.A., Strausser, D.W. and Gabel, G.T. (1998) Post-Traumatic Heterotopic Ossification about the Elbow. Orthopedics, 21, 265-268.

[7] Thompson 3rd, H.C. and Garcia, A. (1967) Myositis Ossificans: Aftermath of Elbow Injuries. Clinical Orthopaedics and Related Research, 50, 129-134.

https://doi.org/10.1097/00003086-196701000-00012

[8] Daugherty, L.C., Bell, J.R., Fisher, B.J., et al. (2013) Radiation Prophylaxis as Primary Prevention of Heterotopic Ossification of the Knee: Classification of Disease and Indications for Treatment. International Journal of Radiation Oncology, 2, 87-94. https://doi.org/10.1007/s13566-012-0077-0

[9] Rader, C.P., Barthel, T., Haase, M., Scheidler, M. and Eulert, J. (1997) Heterotopic Ossification after Total Knee Arthroplasty. 54/615 Cases After 1-6 Years' Follow-Up. Acta Orthopaedica Scandinavica, 68, 46-50. https://doi.org/10.3109/17453679709003974

[10] Toyoda, T., Matsumoto, H., Tsuji, T., Kinouchi, J. and Fujikaw, K. (2003) Heterotopic Ossification after Total Knee Arthroplasty. Journal of Arthroplasty, 18, 760-764. https://doi.org/10.1016/S0883-5403(03)00194-3

[11] Dalury, D.F. and Jiranek, W.A. (2004) The Incidence of Heterotopic Ossification after Total Knee Arthroplasty. Journal of Arthroplasty, 19, 447-452. https://doi.org/10.1016/j.arth.2003.12.064

[12] Furia, J.P. and Pellegrini Jr., V.D. (1995) Heterotopic Ossification Following Primary Total Knee Arthroplasty. Journal of Arthroplasty, 10, 413-419. https://doi.org/10.1016/S0883-5403(05)80139-1

[13] Chidel, M.A., Suh, J.H. and Matejczyk, M.B. (2001) Radiation Prophylaxis for Heterotopic Ossification of the Knee. Journal of Arthroplasty, 16, 1-6. https://doi.org/10.1054/arth.2001.16492

[14] Harwin, S.F., Stein, A.J., Stern, R.E. and Kulick, R.G. (1993) Heterotopic Ossification following Primary Total Knee Arthroplasty. Journal of Arthroplasty, 8, 113-116. https://doi.org/10.1016/S0883-5403(06)80048-3

[15] Chan, P.K., Chiu, K.Y., Ng, F.Y. and Yan, C.H. (2014) Bony Ankylosis of the Knee Secondary to Heterotopic Ossification after Total Knee Arthroplasty: A Case Report. Journal of Orthopaedic Surgery (Hong Kong), 22, 434-436. https://doi.org/10.1177/230949901402200334

[16] Whelan, D.B., Dold, A.P., Trajkovski, T. and Chahal, J. (2014) Risk Factors for the Development of Heterotopic Ossification after Knee Dislocation. Clinical Orthopaedics and Related Research, 472, 2698-2704. https://doi.org/10.1007/s11999-014-3730-7

[17] Stein, D.A., Patel, R., Egol, K.A., Kaplan, F.T., Tejwani, N.C. and Koval, K.J. (2003) Prevention of Heterotopic Ossification at the Elbow Following Trauma Using Radiation Therapy. Bulletin (Hospital for Joint Diseases), 61, 151-154. 
[18] Robinson, C.G., Polster, J.M., Reddy, C.A., et al. (2010) Postoperative Single-Fraction Radiation for Prevention of Heterotopic Ossification of the Elbow. International Journal of Radiation Oncology, Biology, Physics, 77, 1493-1499. https://doi.org/10.1016/j.ijrobp.2009.06.072

[19] Strauss, J.B., Wysocki, R.W., Shah, A., et al. (2011) Radiation Therapy for Heterotopic Ossification Prophylaxis after High-Risk Elbow Surgery. American Journal of Orthopedics, 40, 400-405.

[20] Mourad, W.F., Packianathan, S., Shourbaji, R.A., Russell, G., Khan, M.A. and Vijayakumar, S. (2012) Radiation-Induced Sarcoma Following Radiation Prophylaxis of Heterotopic Ossification. Practical Radiation Oncology, 2, 151-154. https://doi.org/10.1016/j.prro.2011.06.005

[21] Farris, M.K., Chowdhry, V.K., Lemke, S., Kilpatrick, M. and Lacombe, M. (2012) Osteosarcoma Following Single Fraction Radiation Prophylaxis for Heterotopic Ossification. Radiation Oncology, 7, 140. https://doi.org/10.1186/1748-717X-7-140

[22] Berris, T., Mazonakis, M., Kachris, S. and Damilakis, J. (2014) Peripheral Organ Doses from Radiotherapy for Heterotopic Ossification of Non-Hip Joints: Is There a Risk for Radiation-Induced Malignancies? Physics in Medicine, 30, 309-313. https://doi.org/10.1016/j.ejmp.2013.09.003 